\title{
B-mode ultrasonography and ecobiometric parameters for assessment of embryonic and fetal development in sheep
}

\author{
Victor José Correia Santos ${ }^{\mathrm{a}, *}$, Mariana Garcia Kako Rodriguez ${ }^{\mathrm{a}}$, \\ Priscila del Aguila da Silva ${ }^{a}$, Renata Sitta Gomes Mariano ${ }^{a}$, \\ Augusto Ryonosuke Taira ${ }^{\mathrm{a}}$, Vivian Tavares de Almeida ${ }^{\mathrm{b}}$, \\ Ricardo Andrés Ramirez Uscategui ${ }^{\mathrm{b}, \mathrm{c}}$, Ricardo Perecin Nociti ${ }^{\mathrm{a}}$, \\ Pedro Paulo Maia Teixeira ${ }^{\mathrm{d}}$, Marcus Antonio Rossi Feliciano ${ }^{\mathrm{a}, \mathrm{e}}$, \\ Wilter Ricardo Russiano Vicente ${ }^{\mathrm{a}}$
}

\footnotetext{
${ }^{a}$ Department of Animal Reproduction, Faculdade de Ciências Agrárias e Veterinárias - UNESP, Av. Prof. Paulo Donato Castellane S/N, 14884-900, Jaboticabal, SP, Brazil

${ }^{\mathrm{b}}$ Department of Veterinary Clinical and Surgery, Faculdade de Ciências Agrárias e Veterinárias - UNESP, Av. Prof. Paulo Donato Castellane S/N, 14884-900, Jaboticabal, SP, Brazil

${ }^{\mathrm{c}}$ Universidade Federal dos Vales do Jequitinhonha e Mucuri, UFVJM, Avenida Vereador João Narciso 1380, 38610-000, Unaí, MG, Brazil

${ }^{\mathrm{d}}$ Veterinary Medicine College, Universidade Federal do Pará, Av. dos Universitários - Jaderlândia, 68746-360, Castanhal, PA, Brazil

e Universidade Federal do Recôncavo da Bahia, Rua Rui Barbosa 710, 44380-000, Cruz das Almas, BA, Brazil
}

\section{A R T I C L E I N F O}

\section{Keywords:}

Ultrasonography

Gestation

Development

Ewes

\begin{abstract}
A B S T R A C T
The aim in this study was to evaluate the maternal-fetal development during physiological gestation in sheep by means of ultrasonography and to predict the gestational age by mathematical formulae. Thirty Santa Inês sheep were included. Evaluations were performed weekly from the 3rd to 21st gestational week. The Shapiro test was used to determine normality of the data, and Spearman test was used for determining correlations of real or transformed measurements as gestation advanced. If there was a significant difference detected, variable adjustments and gestational weeks were tested using regression models. Significance level was set at $5 \%$ and the results presented as mean \pm SD. Principal components analysis (PCA) was used for data clustering and graphic analysis. The gestational vesicle, abdominal, thoracic, biparietal, ocular orbit, and placentome diameters; and the lengths of crown-to-rump, nuchal to snout, scapula, humerus, radius, metacarpus, femur, tibia, metatarsal, heart length, heart width and kidneys were measured. Using pulsed Doppler ultrasonography, heart rate (HR) was obtained. The greatest coefficients of determination $\left(r^{2}\right)$ were obtained for the biparietal diameter (BPD; 96.5\%) and metacarpus length (MCAR; 93\%), followed by the abdominal diameter (AD; 91.7\%) and heart width (HTW; 90.2\%). The PCA analysis indicated graphically that at week 8 to 9 , there was no significant change related to technique, whereas, at weeks 19, 20, and 21 a decrease in growth was observed, with the greatest data variability at week 19. Ultrasonographic assessments indicated there were significant correlations between developmental stages of all maternal-fetal structures and the gestational age, which can be used as reference values for gestational age assessments and detection of development abnormalities.
\end{abstract}

\footnotetext{
* Corresponding author at: via de acesso Prof. Paulo Donato Castellane s/n, 14884-900, Jaboticabal, São Paulo, Brazil.

E-mail address: santosvjc@gmail.com (V.J. Correia Santos).
} 


\section{Introduction}

Gestational diagnosis, determination of fetal viability, and estimation of gestation period are important in sheep production and research, because these assessments allow for planning and management of flock growth. Ultrasonography is considered a relevant diagnostic tool for gestational examination. Multiple assessments can be made throughout the gestational period using this technique (Valasi et al., 2017); thereby, management practices can be adjusted at any time during the pregnancy.

Ultrasonography was first used for gestational evaluation in sheep in the late 1960's (Lindhal, 1968; Fraser and Robertson, 1968), allowing for accurate gestational diagnosis at 65 days. Subsequently, it was reported that transrectal examination using Doppler technology (Lindhal, 1968) resulted in more accurate diagnoses. The technique was validated for gestational evaluation and determination of fetal viability in 2111 sheep (Lindhal, 1971). Due to technological limitation at the time, however, it was not possible to obtain images representing blood flow. Lindhal (1976), using an ultrasonic device with rudimentary technology, known as B-mode ultrasonography, was able to ascertain 100\% pregnancy-detection rates in 251 sheep and $84 \%$ accuracy for differentiating between single and multiple pregnancies.

Modern ultrasonic devices are more advanced and provide greater quality images. The first signs of gestation in sheep can be identified from the 15th day (Moraes et al., 2008). In earlier studies, such as those of Wilkins (1986), there were similar results, identifying gestation on day 18 and heart rate (HR) on day 24 of gestation.

Ultrasonographic identification of the embryonic and fetal structures or the anatomical divisions can also be used to determine the gestational age, as well as to evaluate if development is typical, thus ascertaining the viability and health of the embryo or fetus. Moraes et al. (2008) and Valasi et al. (2017) could identify intrauterine fluid on day 14 and 21, embryos on day 23 and 25, and HR on day 25 and 26, among other observations. In addition, the time at first observation of the maternal-fetal structures can be used to estimate the gestational age.

Greenwood et al. (2002) studied 32 sheep at an interval of 10 days from gestational day 60 to 120 and reported that the biparietal diameter (BPD) and metacarpus length (MCAR) allowed for precise estimation of the gestational age in days ( $\left.r^{2}=95 \%\right)$. Metodiev et al. (2012) studied dairy ewes between gestation day 25 and 63, and reported a similar correlation ( $r=0.93)$ for the BPD and biparietal craniocaudal length $(r=0.84)$.

Considering the importance of ultrasonographic gestational diagnoses and as well as subsequent gestational assessment and the limited availability of studies evaluating the entire gestational period in sheep, the aim of the present study was to evaluate gestational development in sheep. Furthermore, the present study allowed for obtaining reference values for use in health assessment of the sheep embryo and fetus and to derive mathematical formulae for estimating the gestational age.

\section{Materials and methods}

This study was approved by the Animal Ethic and Welfare Committee (Univ Estadual Paulista) protocol № 11708-14. Thirty Santa Inês ewes, pluriparous and adult (age, 2-5 years), with an average body weight of $45.4 \pm 4.3 \mathrm{~kg}$, belonging to the Department of Preventive Veterinary Medicine and Animal Reproduction, were included. The sheep were declared healthy based on results from clinical background evaluation, physical examinations, and hematological tests.

Ewes were maintained in an elevated sheep house, and fed with corn silage, commercial food, and water ad libitum. Thirty days before the experimental period, to adapt animals to the experiment routine and reduce handling-induced stress, the subjects underwent abdominal trichotomy and transrectal and transabdominal ultrasonic examination once a week.

After the adaptation period, the animals were submitted to an estrus synchronization protocol (Souza et al., 2007; Fig. 1). After $24 \mathrm{~h}$, the ewes were allocated for a period of 2 days with a ram of proven reproductive efficiency. For the identification of mated females, a mixture of soybean oil and dye was applied on the ram's chest.

The day after mating was considered as gestational day 1 and gestational day 21, transrectal ultrasonic examination was performed for gestational diagnosis. If pregnancy was confirmed, weekly ultrasonographic evaluations started immediately, with animals physically restrained in the quadrupedal position. Examinations were performed transrectally with the MyLab ${ }^{\mathrm{TM}} 30 \mathrm{VET}^{\mathrm{T}}$ device (Esaote, Genova, Liguria, Italy) and a linear probe (7.5 MHz) until gestation week 8. From gestation week 9 to the time of parturition, a linear transducer (7.5 MHz) was used transabdominally.

Transrectal probe was used until gestation week 8. Because the uterus is located more dorsally at this pregnancy stage, the closeness of the probe facilitated the acquisition of clear images. In addition, the abdomen was positioned over the operator's leg so that the distance between uterus and transducer was reduced. A transabdominal transducer was used from week 9 onward to prevent discomfort caused by the previously described positioning and because the uterus was located closer to the abdominal wall due to

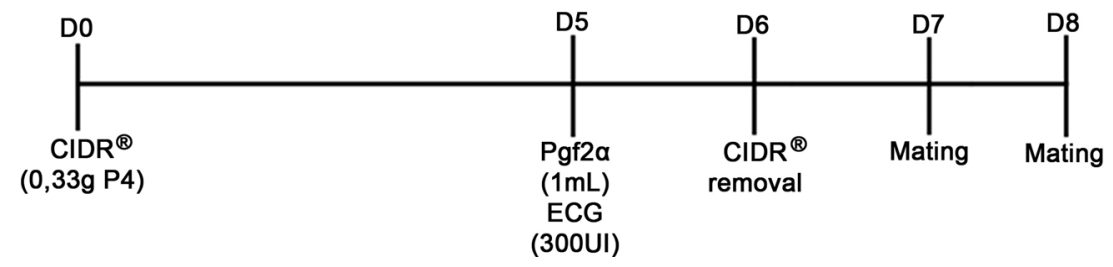

Fig. 1. Illustration of the short synchronization protocol of estrus and natural mating in sheep. 
weight gain.

Ultrasonic examinations were performed on longitudinal and transverse sections to identify the uterus, placentomes, and embryonic or fetal structures (the gestational vesicle, abdomen, thorax, ocular orbit, scapula, humerus, radius, metacarpus, femur, tibia, metatarsus, kidneys, heart, lungs, liver, intestines, and gastric chambers). The embryonic period was defined as gestation day 11 to 34 (Jainudeen and Hafez, 2000), and the fetal period, from gestation day 35 (Hafez and Hafez, 2000).

Once each of the described structures was located, the gestational age of the first visualization was recorded and all images were saved on the ultrasonic equipment. After examination, the following structures were measured (in mm): gestational vesicle diameter (GV), abdominal diameter (AD), thoracic diameter (TD), BPD, ocular orbit diameter (OO), placentome diameter (PL), nuchal-to-snout length (NS), scapular length (SCA), humerus length (HUM), radius length (RAD), MCAR, femur length (FEM), tibia length (TI), metatarsus length (MTAR), and kidney length (KD). HR in beats/min was obtained by means of pulsed Doppler ultrasonography. In addition, measurements (in $\mathrm{mm}$ ) were made of the heart length from the base to apex (HTL) and the heart width of the left to right wall in the region closest to the base (HTW).

Statistical analysis was performed using R-project software ( $\mathrm{R}^{\circledR}$ Foundation for Statistical Computing, Austria). Distribution of the parameters was initially tested using the Shapiro test. Subsequently, real or transformed measurements were correlated with gestational week using the Spearman test. For significant correlations, variable adjustments and gestational weeks were tested using regression models (linear, quadratic, and cubic). For the variables where graphical analysis indicated there was a plateau in relation to the gestational age, a ROC (receiver-operating characteristic) curve analysis was performed using gestational weeks as a reference for the calculation of cut-off point, sensitivity, and specificity in the prediction of the gestational period after this plateau. The level of significance was set at $5 \%$ for all tests and results are presented as the mean \pm SD (standard deviation). Principal components analysis was used for data clustering and graphic analysis.

\section{Results}

The evaluation of 30 sheep indicated 22 single, seven twin, and one triplet pregnancy. All pregnancies were full-term, births occurred without intervention, and all 39 lambs were born healthy.

At the time of the first evaluation, it was possible to visualize the embryo, gestational vesicle, heart beats, and placentomes, although these did not have the typical 'C' or 'O' format (Fig. 2). The embryo was recongized as an echogenic structure in contact with the uterus and its heart could be identified as a small region that had rapid movement (heart beats). At this gestational stage, it was

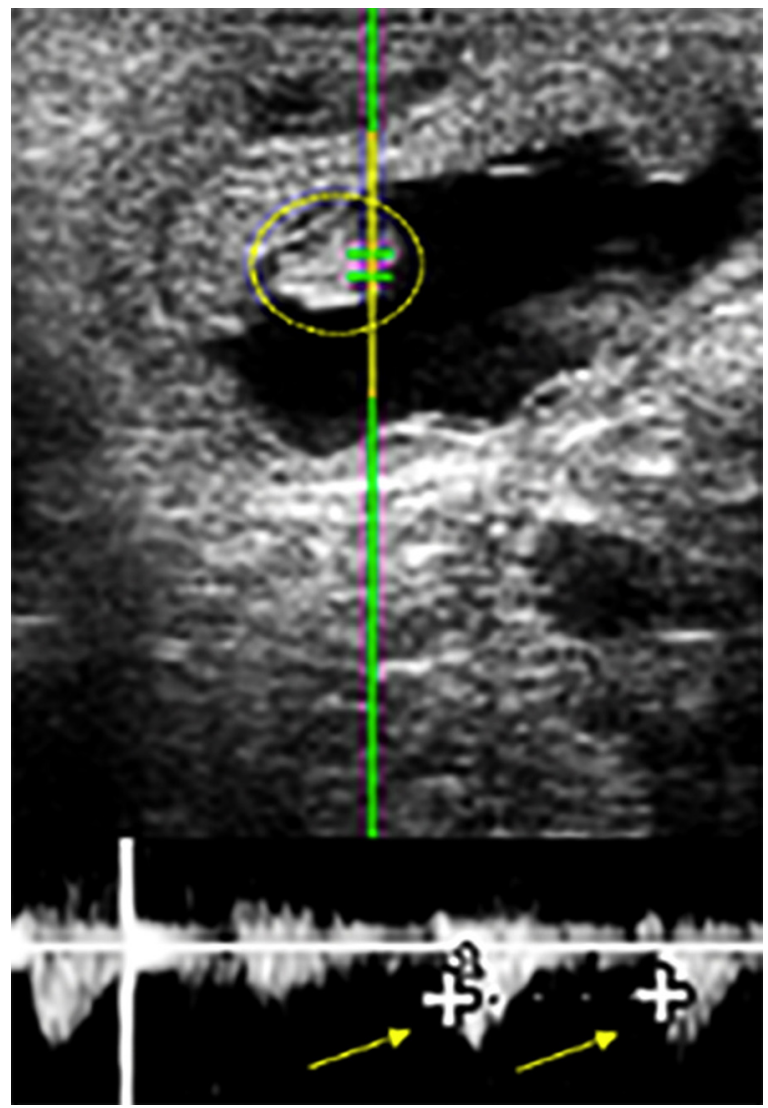

Fig. 2. B-mode ultrasonographic image of a sheep uterus at 3 weeks of gestation; Embryo (dotted circle) and Doppler tracing (arrows). 


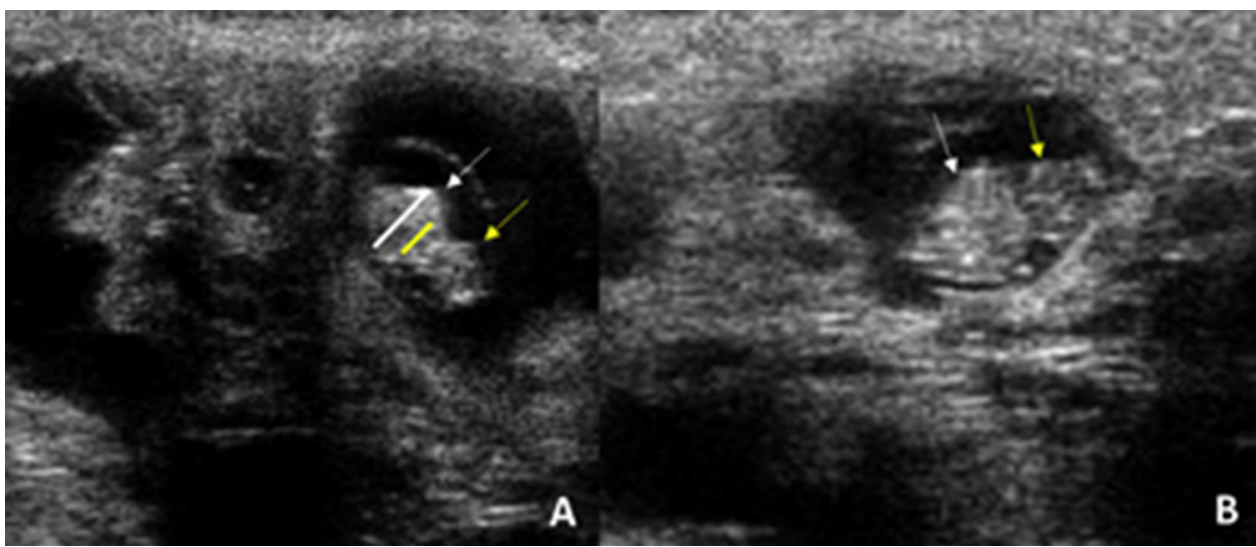

Fig. 3. B-mode ultrasonographic image of a sheep uterus at 4 weeks of gestation; A: yellow arrow (head), white arrow (trunk), yellow line (thorax), and white line (abdomen); B: yellow arrow (head); white arrow (chest) (For interpretation of the references to colour in this figure legend, the reader is referred to the web version of this article).

also possible to measure the crown-to-rump length.

In some animals, it was possible to measure the heart size at week 4 of gestation. At this time, the abdomen, thorax, head, and trunk were clearly differentiated (Fig. 3). In the 6th week of gestation, the kidneys were detected in some fetuses (Fig. 4) and the femur, humerus, tibia, radius, metacarpus, and metatarsus were visualized. At the $7^{\text {th }}$ week of gestation, the GV and crown-to-rump length could no longer be measured due to the increase in fetal size, and the pulmonary structures were visualized (Fig. 4).

From the 8th to 15th week of gestation, it was possible to perform biometry assessments of most target organs. From week 13 of gestation onward, however, it was difficult to measure the NS due to fetal size, and from week 16 of gestation onward, bone identification became difficult, not only due to fetal size but also due to ultrasonographic characteristics, positioning difficulty, and fetal movement. For most of the evaluated structures, obtaining satisfactory images that allowed for determination of values for the stage of gestation gradually became more difficult with the advancement of gestation.

The PCA indicated clustering of data by week. At week 8-9, the data were proximal. This finding highlights the observation of a decreased growth rate at weeks 19, 20, and 21 of gestation and greatest data variability on week 19 of gestation (Fig. 5). Data for gestational age at which it was possible to visualize and identify the maternal-fetal anatomical structures for the first time by ultrasonographic examination are presented in Table 1.

For the period in which it was possible to determine values for each of the variables, the regression models accurately estimated gestational age. Coefficients of determination for each of these models are provided in Table 2. The values for all variables were correlated with gestational weeks $(P<0.001$ and $r>0.500)$. Parameters and regression models of the variables that had determination coefficients of $>90 \%\left(r^{2}>90 \%\right)$, as well as the HR, are depicted in Fig. 6 .

Graphical analyses of HR, BPD, and PL behavior (Fig. 7) indicated there was a lack of linearity during the respective measurement

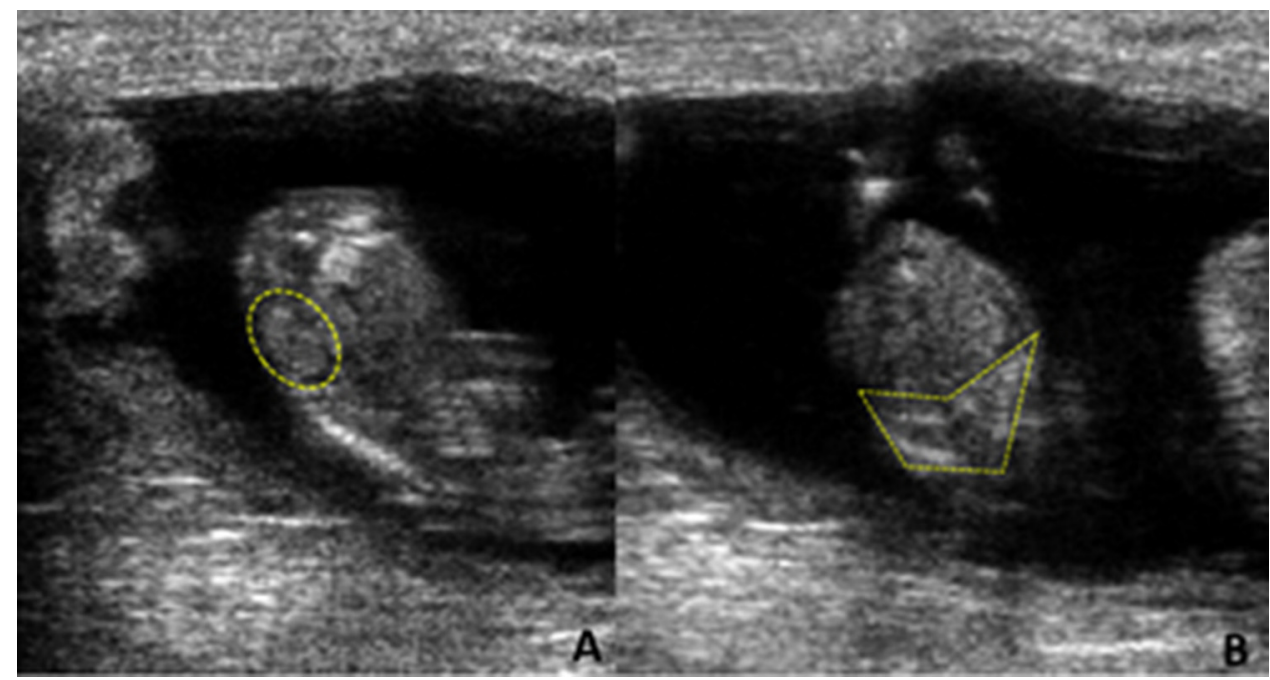

Fig. 4. A: B-mode ultrasonographic image of the sheep uterus at 6 weeks of gestation; Dotted circle delineates the kidney; B: B-mode ultrasonographic image of the sheep uterus at 7 weeks of gestation Polygon delineates the lungs. 


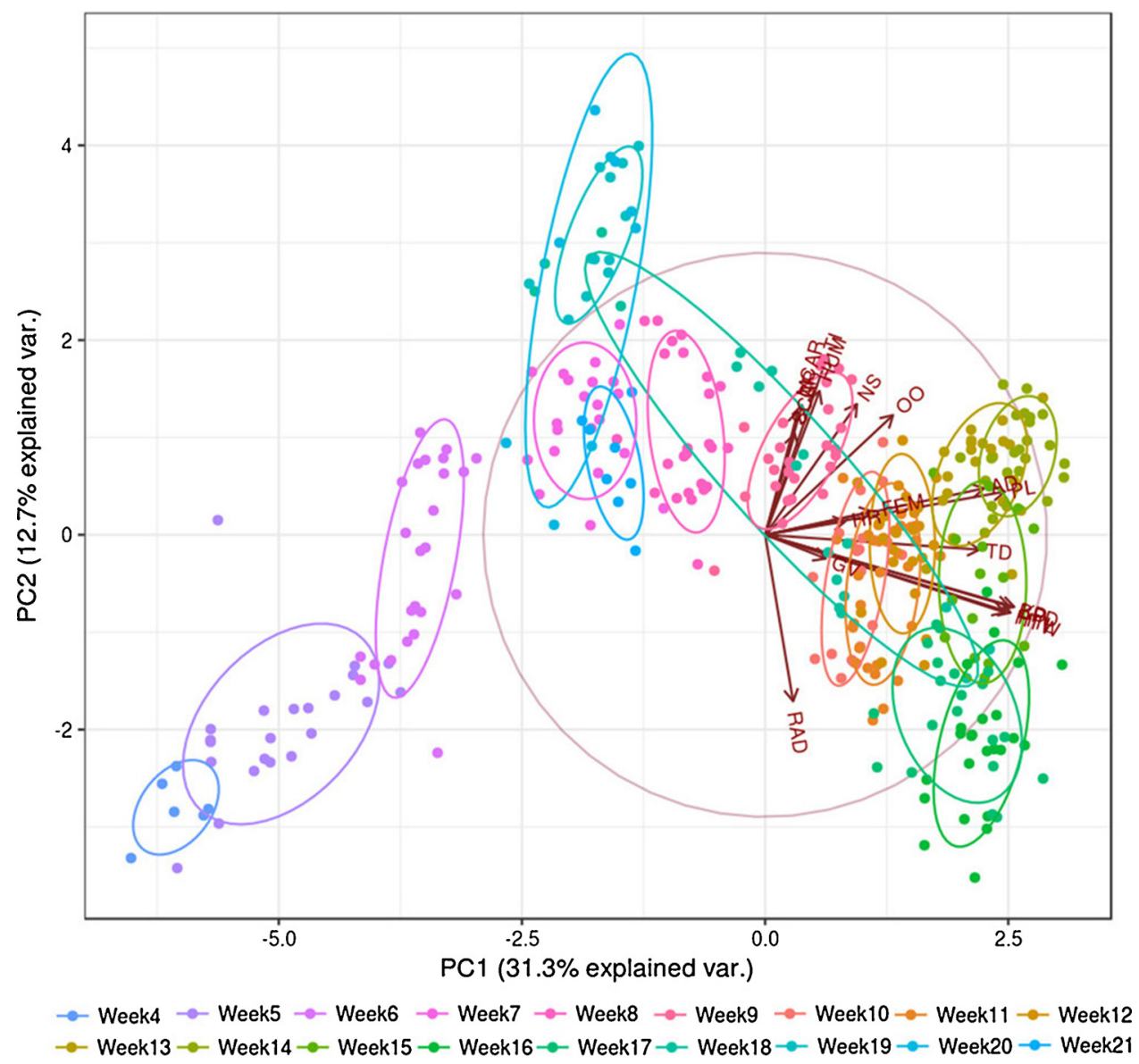

Fig. 5. Principal components analysis of the assessed variables; Data are clustered in gestational weeks; Changes in growth pattern are visible as the gestation progresses.

Table 1

Time (gestational week) of first visualization of the maternal-fetal structures by B-mode ultrasonography in Santa Inês sheep.

\begin{tabular}{llll}
\hline Structure & GW & Structure & GW \\
\hline Embryo & 3 & Fetal movements & 6 \\
Placentome & 3 & Limb bones & 6 \\
Heart beats & 3 & Ribs & 6 \\
Gestational vesicle & 3 & Prominent limbs & 6 \\
Heart & 4 & Nose & 6 \\
Abdomen & 4 & Lungs & 7 \\
Head & 4 & Stomach chambers & 7 \\
Head/trunk differentiated & 4 & Intestinal mass & 8 \\
Neural tube & 5 & Liver & 8 \\
Ocular orbit & 5 & Vertebral column & 8 \\
Umbilical cord & 5 & Kidney pyramids & 11 \\
Thorax & 6 & Intestinal loops & 12 \\
Kidneys & 6 & Bronchial tree & 15 \\
\hline
\end{tabular}

GW: gestational week.

${ }^{\mathrm{a}}$ Except scapula.

period. The ROC curve analysis, therefore, was performed to determine if a cut-off value for each could indicate the specific gestational period. Thus, HR $<144$ beats/min is indicative of the final week of gestation, with sensitivity of $93 \%$, specificity of $95 \%$, and area under the curve of $95 \%$; BPD $>47.4 \mathrm{~mm}$ is indicative of gestation week $>17$, with sensitivity of $100 \%$, specificity of $92.5 \%$, and area under the curve of $97.2 \%$; and PL diameter $>22.3 \mathrm{~mm}$ suggests gestational age $>9$ weeks, with sensitivity of $91.5 \%$, specificity of $80.7 \%$, and area under the curve of $92.6 \%$. 
Table 2

Fetal biometry by means of ultrasonography and equations for the determination of gestational age in Santa Inês sheep.

\begin{tabular}{|c|c|c|c|}
\hline Variable & GW & $r^{2}(\%)$ & Predictive Equation \\
\hline BPD & $4-17$ & 96.5 & $G W=3.7+0.3 \times B P D$ \\
\hline MCAR & $7-15$ & 93.0 & $G W=7.0+0.2 \times M C A R$ \\
\hline $\mathrm{AD}$ & $4-21$ & 91.7 & $G W=3.9+0.2 \times A D$ \\
\hline TD & $6-21$ & 91.3 & $G W=4.8+0.2 \times T D$ \\
\hline RAD & $7-18$ & 91.2 & $G W=7.1+0.2 \times R A D$ \\
\hline MTAR & $7-16$ & 90.3 & $G W=7.4+0.2 \times M T A R$ \\
\hline HTW & $4-21$ & 90.2 & $G W=4.9+0.5 \times H T W$ \\
\hline FEM & $7-16$ & 89.0 & $G W=7.1+0.2 \times F E M$ \\
\hline HUM $^{\mathrm{a}}$ & $7-16$ & 88.9 & $G W=7.2+0.2 \times H U M$ \\
\hline NS & $6-14$ & 88.7 & $G W=4.8+0.1 \times N S$ \\
\hline $\mathrm{KD}$ & $7-20$ & 88.0 & $G W=4.8+0.4 \times K D$ \\
\hline $\mathrm{SCA}^{\mathrm{a}}$ & $8-14$ & 87.6 & $G W=7.2+0.3 \times S C A$ \\
\hline HTL & $4-21$ & 87.3 & $G W=5.1+0.4 \times H T L$ \\
\hline TI & $7-14$ & 82.6 & $G W=7.2+0.2 \times T I$ \\
\hline $\mathrm{OO}$ & $6-14$ & 81.8 & $G W=6.0+0.4 \times O O$ \\
\hline CR & $3-7$ & 80.4 & $G W=2.65+0.11 \times C R$ \\
\hline PL & $3-8$ & 71.6 & $G W=3.6+0.2 \times P L$ \\
\hline GV & $3-7$ & 68.9 & $G W=3.1+0.1 \times G V$ \\
\hline $\mathrm{HR}^{\mathrm{b}}$ & $3-21$ & 46.3 & $G W=-75.9+1.9 \times H R-0.01 \times H R^{2}+0.00003 \times H R^{3}$ \\
\hline
\end{tabular}

GW: gestational week, $r^{2}$ : determination coefficient, BPD: biparietal diameter, MCAR: metacarpus length, AD: abdominal diameter, TD: thoracic diameter, RAD: radius length, MTAR: metatarsus length, HTW: heart width, FEM: femur length, HUM: humerus length, NS: nuchal-to-snout length, KD: kidney length, SCA: scapula length, HTL: heart length, TI: tibia length, OO: ocular orbit, CR: crown-to-rump length, PL: placentome diameter, GV: gestational vesicle, HR: heart rate.

${ }^{a}$ Difficult to measure from 180 expected measures, only 44 were performed.

b This variable's behavior was explained by a cubic regression model and, therefore, was non-linear like the other parameters All variables were measured in millimeters, except heart rate (beats/min).

\section{Discussion}

During the first weeks of pregnancy, development of the embryo/fetus is too incipient; therefore, only after a few weeks, data clustering is observed. The PCA revealed that changing the method of examination from intrarectal to transabdominal at week 9 does not influence the results obtained. Furthermore, this change provides more physical comfort and less stress which is reported to be harmful to the fetus (Elmetwally et al., 2016). In addition, a decrease in developmental rate was observed at $\geq 19$ week.

All values for maternal-fetal ultrasonographic variables were significantly correlated with gestational weeks and allowed for the estimation of gestational age with variable accuracy during different gestational periods. Among these parameters, only the AD and heart width (HTW) were measurable from gestation week 4 to 21 and allowed for estimation of the gestational age by means of a linear regression model (Table 2) with a coefficient of determination $>90 \%$. Thus, these two variables, during most of the gestation period, allowed for estimation of the gestational age within a $10 \%$ margin of error. In addition, the results of the present study indicate the gestational week in which many maternal-fetal anatomical structures, organs, and regions of interest are first detected by ultrasonic evaluation.

Carr et al. (2011) reported that AD appeared to be the single variable with a significant correlation to fetal growth in sheep $\left(r^{2}=82.5 \%\right)$, which was consistent with results $\left(r^{2}=91.7 \%\right)$ from the present study based on the entire gestational period. By limiting the period of evaluation to that of the earlier study, $\mathrm{AD}$ is ranked as the third most reliable variable among those assessed in the current study. This result is similar to that between the $8^{\text {th }}$ and $19^{\text {th }}$ gestational weeks reported by Barbera et al. (1995).

Greenwood et al. (2002) and Metodiev et al. (2012) reported that BPD is the most reliable variable to estimate the gestational age in sheep, with determination coefficients of $95 \%$ and $83 \%$ at gestation week 7-17 and gestation week 6 to 9 , respectively, which is consistent with results in the present study. In the current study, the BPD had the greatest determination coefficient for the gestational age $\left(r^{2}=96 \%\right)$ among the variables studied, however, it is only applicable between the 4th and 17th gestational weeks, when measurement is possible.

Greenwood et al. (2002) likewise reported that the MCAR was a reliable predictor of the gestational age with coefficient of determination of $94 \%$, similar to findings in the present study $\left(r^{2}=93 \%\right)$. The parameter ranked second among the variables studied. This parameter, however, is only reliable between the 7 th and 15th gestational weeks, when it is possible to identify the bone with certainty.

The TD was the fourth most reliable parameter among the variables studied, with coefficient of determination of $91.3 \%$, and comparable accuracy with that of $\mathrm{AD}$; however, sbecause the TD is only measurable at gestation week $>6$, when the ribs become visible, its applicability is limited as compared to that of the $\mathrm{AD}$, at gestation week 2. Bulnes et al. (1998) reported a correlation of $96 \%$ for the TD.

Biometry of the heart is very relevant for estimation of the gestational age, with determination coefficients of $90.2 \%$ for the HTW and 87.3 for the heart length, ranking $7^{\text {th }}$ and $13^{\text {th }}$ on the reliability scale in the present study. Importantly, these parameters are 
A)

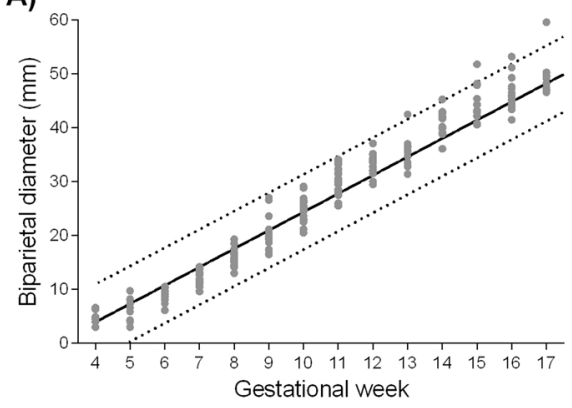

C)

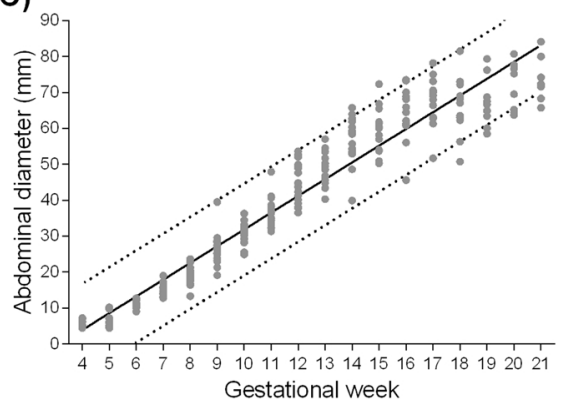

E)

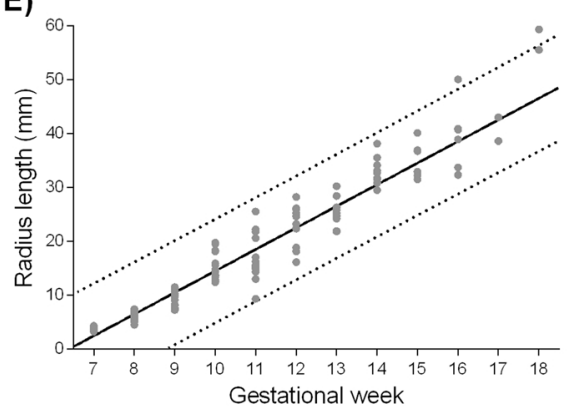

G)

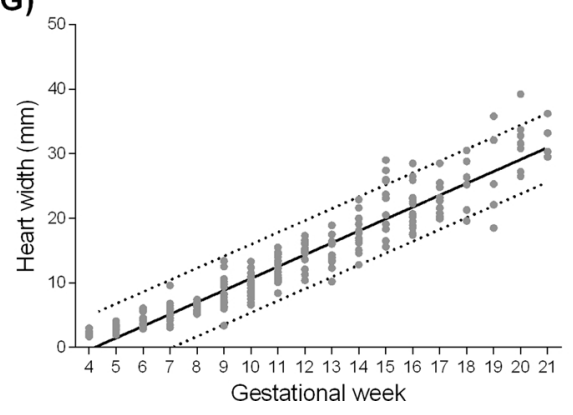

B)

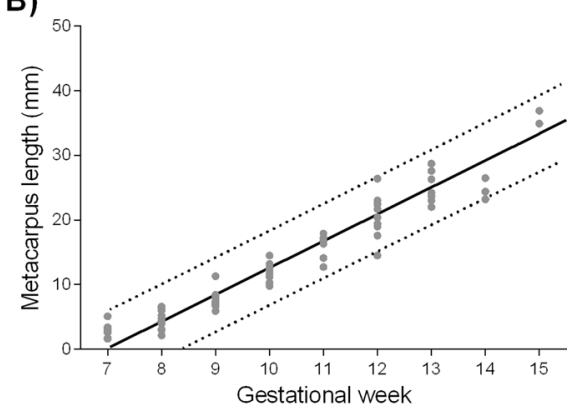

D)



F)

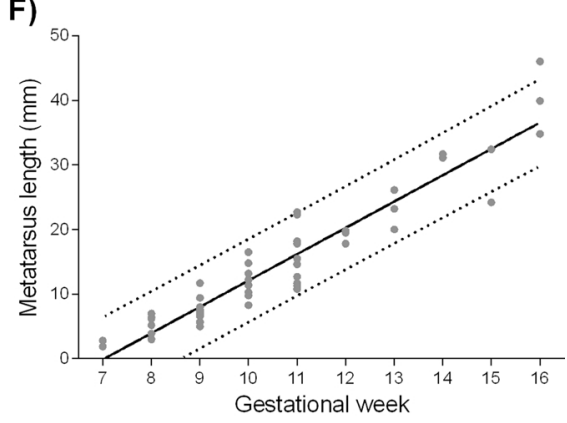

H)

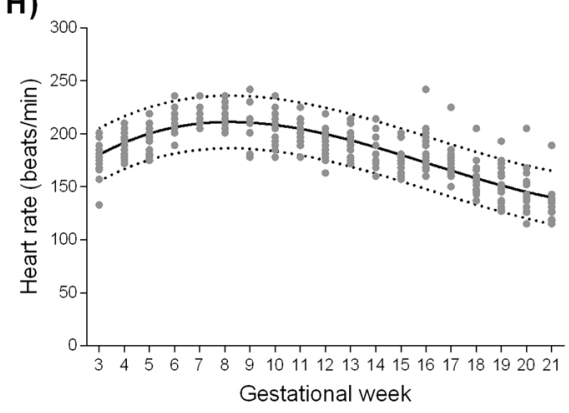

Fig. 6. Graphical representation of the trajectory of values for variables with determination coefficients of $>90 \%$ and heart rate throughout pregnancy; Variables were evaluated weekly by means of ultrasonography in 30 healthy Santa Inês sheep; Continuous lines represent the regression model adapted to this parameter; Dotted lines indicate the prediction bands at 95\% confidence; A) Biparietal diameter, B) Metacarpus length, C) Abdominal diameter, D) Thoracic diameter, E) Radius Length, F) Metatarsus length, G) Heart width, and H) Heart rate (beats/min).

measurable almost throughout the gestational period in sheep (week 4-21). With respect to ruminants, these variables have been reported in cows (Lazim et al., 2016) and mini-goats (Kandiel et al., 2015). There, therefore, were reliable determination coefficients ( $r^{2}=97 \%$ and 95\%, respectively) in the previous study that were similar to that for the HTW in the present study, which was more reliable than that for HTL $\left(r^{2}=93 \%\right)$ in mini-goats.

The FEM and TI had determination coefficients of $89 \%$ and $82.6 \%$, respectively, and were visible from gestation week 7 to 16 . These results are not consistent with those of Barbera et al. (1995), where it was reported that the FEM had a determination 

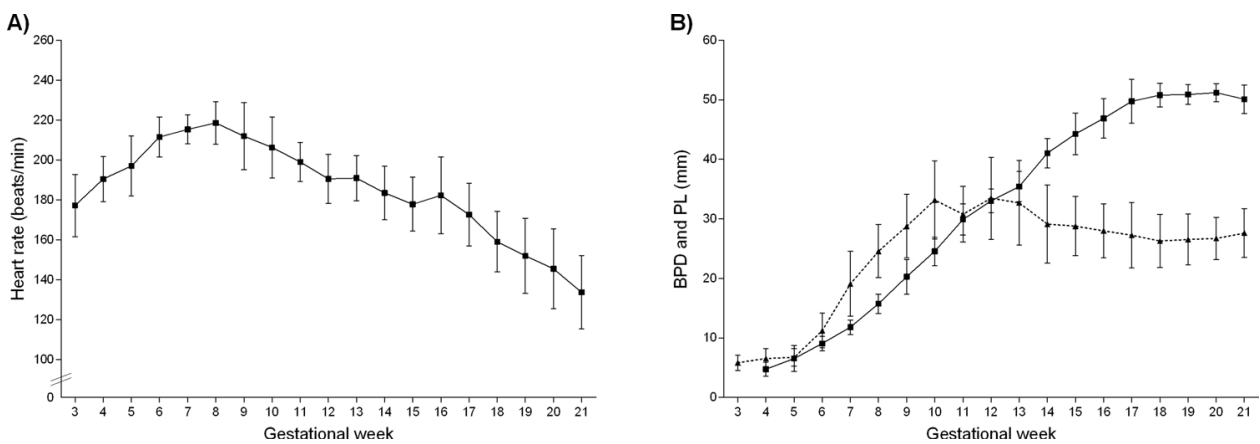

Fig. 7. Graphic representation of the mean and SD of A) heart rate (beats/min) and B) biparietal diameter (BPD, continuous line), and placentome diameter (PL, dotted line); Variables were measured weekly throughout pregnancy by means of ultrasonography in 30 healthy Santa Inês ewes.

coefficient of $43.5 \%$ and the TI had determination coefficient of $60.4 \%$, between the 8 th and the 19 th weeks of gestation, and those reported by James et al. (2015) for the femur $\left(r^{2}=98.7 \%\right)$ between the 5 th and 16th weeks of gestation. These measurements, however, may have little value in determining the gestational age, because visualization of bones is hampered by fetal growth and movement and occurrence of ultrasonic artifacts could hinder and even impede proper identification of these structures, which may explain the observed variation among the studies that were previously described in this manuscript.

The NS resulted in a determination coefficient of $88.7 \%$ to estimate the gestational age between the 6 th and 14 th gestational weeks, the crown-to-rump length coefficient was $80.4 \%$ between the 3rd and 7 th weeks, and the OO coefficient was $81.8 \%$ between the 6th and 14th weeks of gestation. These parameters were considered less accurate to estimate the gestational age than as described by Bulnes et al. (1998) for the same evaluation periods $\left(r^{2}=95 \%, 94 \%, 92 \%\right.$, respectively). These discrepancies could be explained by differences in breeds of sheep between studies. Although the determination coefficients of those variables were acceptable, it is not possible to measure these during most of the gestational period, due to fetal size and movement, which makes it difficult to acquire high quality images, thereby limiting use in estimation of the gestational age.

The kidneys were measurable from week 7 to 20 with moderate accuracy $\left(r^{2}=88 \%\right)$ to estimate the gestational age. Bulnes et al. (1998) and Ali and Hayder (2007) reported results similar to those of the present study ( $r^{2}=82.0 \%$ and $80.5 \%$, respectively) but there was no description of the applicability of this variable, probably due to its limited efficacy compared to the other parameters. Carr et al. (2011) reported that the renal volume has potential for use in the estimation of fetal growth.

The PL was moderately reliable $\left(r^{2}=71.6 \%\right)$ to estimate the gestational age between the $3^{\text {rd }}$ and 8 th week. After this period, the PL exceeded $22.3 \mathrm{~mm}$ and its growth did not correlate with the gestational age. With the advancement of gestation, visualizing larger placentomes is increasingly difficult, furthermore, consistent evaluation of the placentome throughout pregnancy is not possible. These findings corroborate the results reported by Bulnes et al. (1998), where there was a description of the large amount of variation in the size of placentomes between the 5th and 13th weeks of gestation, and those of Doizé et al. (1997), where it was reported that there was a low coefficient of determination $\left(r^{2}=15.6 \%\right)$ between the PL and gestational age between the 5th and 13th weeks.

With regard to the GV, Bulnes et al. (1998) reported a determination coefficient of $76 \%$ to estimate the gestational age between the 3rd and 5th weeks. That result is comparable to the results of the present study $\left(r^{2}=68.9 \%\right)$ between the $3^{\text {rd }}$ and $7^{\text {th }}$ week of gestation, indicating that the GV is a less relevant parameter for estimation of the gestational age in sheep compared to other domestic species, such as dogs and cats (Beccaglia et al., 2016).

For HR, there was a moderate correlation with gestational age $(r=-0.65)$ and its frequency during gestation (week 3 to 21$)$ is explained by a cubic regression model $\left(r^{2}=46.3 \%\right)$, with gradual increases until the 8th week of gestation and subsequently, gradual decreases until the 21st week. Godfrey et al. (2010) reported a similar coefficient of determination $\left(r^{2}=39 \%\right)$ using a cubic model between the 3rd and 10th gestational weeks. Although HR does not allow adequate estimation of the gestational age in goats, this variable may be useful in assessing fetal viability based on the findings of Moreno et al. (1996) and as an indicator of fetal maturity, as inferred from a study by Unno et al. (1999). From these previous studies, the function was ascertained of fetal cortisol during the final gestational period (day 120 until parturition) and was determined to be partially responsible for the ontogenic increase of blood pressure and reflex HR reduction (178 \pm 2 beats/min at day 120 to $143 \pm 2$ beats/min at day 140). Fetal cortisol is considered a necessary factor for postnatal cardiovascular function. Likewise, results of the present study indicate that a HR of $<144$ beats/min was an accurate indicator (sensitivity, 93\%; and specificity, 95\%) of the last week of gestation and this finding is consistent with the previously reported values for this period in sheep (Aiumlamai et al., 1992; Moreno et al., 1996).

The time at which the maternal-fetal anatomical structures (e.g. placentomes or fetal intestinal loops) or pregnancy-related events (e.g. fetal movement) are identified may assist in both the estimation of gestational age and the evaluation of embryonic and fetal development. These events were previously described by Moraes et al. (2008) in Santa Inês sheep between gestation day 15 and 45 , and by Valasi et al. (2017) in Chios-cross ewes during the entire gestational period.

The results from these previous studies are consistent with observations in the present study; however, with the experimental conditions in the present study, it was possible to identify the placentomes and heart beats and differentiate between the head and trunk 1 week earlier (3rd compared with 4th week of gestation); between the thoracic cavity and abdomen, 2 weeks earlier (3rd compared with 5th week of gestation); the kidneys, 5 weeks earlier (6th compared with 11th week of gestation), and the lungs, 8 
weeks earlier (7th compared with 15th week of gestation). The different timing of events that was previously described in this manuscript may result from differences as compared with findings in the present study in the image quality ultrasonic equipment used, technique for obtaining the images, frequency of examinations, or evaluation period. Another factor that affects the results obtained is the experience of the operator. Experienced operators can be more efficient in identifying structures with greater certainty.

Even though acceptable coefficients of determination (88.9\% and $87.6 \%$, respectively) were determined in the present study, the length of the scapula and humerus are technically difficult to assess and the period in which these are applicable in making this determination is quite limited. Studies evaluating these measures for the estimation of gestational age have not been previously reported. These determinations, therefore, are less relevant for this purpose. In similar species, such as goats, Rihab et al. (2012) and Léga et al. (2007) reported that the HUM allowed for accurate estimation ( $\left.r^{2}=95 \%\right)$ of the gestational age, while the scapula length was considered to be of limited value $\left(r^{2}=80.0 \%\right)$ for this purpose, as compared to the other variables.

Knowledge of the physiology of gestation facilitates the diagnosis of abnormalities. Thus, the overall findings in the present study have the potential use in gestational assessment, strategic decision making in sheep production, and developing interventions to ensure the health of ewes and the offspring.

Variables with lineartrajectories of change, besides being useful for the estimation of the gestational age, can also be used to ascertain normal fetal development. Values that are outside the expected range, may be used to predict the occurrence of developmental abnormalities. These linear variables include the biparietal, abdominal, and thoracic diameters; the metacarpus, radius, and metatarsus lengths; and the HTW. With regard to reliability, the applicable period for effectiveness of determinations when using each variable, should be considered. The $\mathrm{AD}$ and $\mathrm{HTW}$ are the most reliable variables for estimating the gestational age, as these are measurable from gestation week 4 to 21 .

\section{Conclusion}

All maternal-fetal ecobiometric variables evaluated were correlated with the gestational age. Biparietal diameter and length of the metacarpus were the most accurate variables for estimation of the gestational age. Evaluation of these parameters, however, is possible only from gestation week 4 to 17, whereas, the AD and HTW allow for estimation with similar accuracy for most of the gestational period (week 4 to 21). It was also possible to identify maternal-fetal structures and events earlier than the time-points reported in previous studies, such as the placentomes, kidneys, lungs, heartbeat, and differentiation between the head, thorax, and abdomen. The results from the present study have potential for use in the estimation of gestational age, evaluation of embryonic and fetal development, and identification of alterations in the gestational process in Santa Inês sheep.

\section{Conflict of interest}

The authors report no conflict of interest.

\section{Acknowledgements}

Fundação de Amparo à Pesquisa do Estado de São Paulo (FAPESP) for scholarship (2014/15422-0) and Coordenação de Aperfeiçoamento de Pessoal de Nível Superior (CAPES) provided scholarship funds.

\section{References}

Aiumlamai, S., Fredriksson, G., Nilsfors, L., 1992. Real-time ultrasonography for determining the gestational age of ewes. Vet. Rec. 131, 560-562. Ali, A., Hayder, M., 2007. Ultrasonographic assessment of embryonic, fetal and placental development in Ossimi sheep. Small Rumin. Res. 73, 277-282.

Barbera, A., Jones III, O.W., Zerbe, G.O., Hobbins, J.C., Battaglia, F.C., Meschia, G., 1995. Ultrasonographic assessment of fetal growth: comparison between human and ovine fetus. Am. J. Obstet. Ginecol 173, 6.

Beccaglia, M., Alonge, S., Trovo, C., Luvoni, G.C., 2016. Determination of gestational time and prediction of parturition in dogs and cats: an update. Reprod. Domest. Anim. 51, 12-17.

Bulnes, A.G., Moreno, J.S., Sebastian, A.L., 1998. Estimation of fetal development in Manchega dairy ewes by transrectal ultrasonographic measurements. Small Rumin. Res. 27, 243-245.

Carr, D.J., Aitken, R.P., Milne, J.S., David, A.L., Wallace, L.M., 2011. Ultrasonographic assessment of growth and estimation of birthweight in late gestation fetal sheep. Ultrasound Med. Biol. 37, 1588-1595.

Doizé, F., Vaillancourt, D., Carabin, H., Bélanger, D., 1997. Determination of gestational age in sheep and goats using transrectal ultrasonographic measurement of placentomes. Theriogenology 48, 449-460.

Elmetwally, M., Rhon, K., Meinecke-tillmann, S., 2016. Doppler Sonography is a useful method to assess the effects of maternal anxiety on intrauterine fetal growth in pregnant sheep and goats. Qual. Prim. Care 24, 137-145.

Fraser, A.F., Robertson, J.G., 1968. Pregnancy diagnosis and detection of fetal life in sheep and pigs by an ultrasonic method. Br. Vet. J. 724, $239-244$.

Godfrey, R.W., Larson, L., Weis, A.J., Willard, S.T., 2010. Evaluation of ultrasonography to measure fetal size and heart rate as predictors of fetal age in hair sheep. Sheep Goat Res. J. 25, 60-65.

Greenwood, P.L., Slepetis, R.M., McPhee, M.J., Bell, A.W., 2002. Prediction of stage of pregnancy in prolific sheep using ultrasound measurement of fetal bones. Rep. Fert. and Develop. 14, 7-13.

Reproductive cycles. In: Hafez, E.S.E., Hafez, B. (Eds.), Reproduction in Farm Animals, 7ed. Lippincott Williams \& Wilkins, Philadelphia, pp. 55-67.

Jainudeen, M.R., Hafez, E.S.E., 2000. Gestation, prenatal physiology, and parturition. In: Hafez, E.S.E., Hafez, B. (Eds.), Reproduction in Farm Animals, 7 ed. Lippincott Williams \& Wilkins, Philadelphia, pp. 140-155.

James, A.A., Chom, N.D., Fadason, S.T., Andrew, A., Emmanuel, E.G., 2015. Ultrasonographic determination of gestational age in Yankasa Ewes. J. Anim. Vet. Adv. 5 , 1169-1175. 
Kandiel, M.M.M., Watanabe, G., Taya, K., 2015. Ultrasonographic assessment of fetal growth in miniature "Shiba" goats (Capra hircus). Anim. Reprod. Sci. 162, 1-10. Lazim, E.H., Alrawi, H.M., Aziz, D.M., 2016. Relationship between gestational age and transabdominal ultrasonographic measurements of fetus and uterus during the $2^{\text {nd }}$ and $3^{\text {rd }}$ trimester of gestation in cows. Asian. Pac. J. Reprod. 5, 326-330.

Léga, E., Toniollo, G.H., Oliveira, J.A., Resende, K.T., Rodrigues, V., 2007. Determinação da idade fetal por meio da técnica ultra-sonográfica de fetometria e de morfologia fetal em cabras. Arq. Bras. Med. Vet. Zootec. 59, 851-856.

Lindhal, I.L., 1968. Pregnancy diagnosis in ewes in continual breeding. J. Anim. Sci. 27, 1511.

Lindhal, I.L., 1971. Pregnancy diagnosis in the ewe by intrarectal Doppler. J. Anim. Sci. 52, 922-924.

Lindhal, I.L., 1976. Pregnancy diagnosis in ewes by ultrasonic scanning. J. Anim. Sci. 45, 1135-1140.

Metodiev, N., Dimov, I., Ralchev, I., Raicheva, E., 2012. Measurements of foetal growth via transabdominal ultrasonography during first half of pregnancy at ewes from synthetic population Bulgarian milk. Bulg. J. Agric. Sci. 18, 4.

Moraes, E.P.B.X., Dos Santos, M.H.B., Aguiar Filho, C.R., Neves, J.P., Oliveira, M.A.L., De Lima, P.F., 2008. Avaliação ultra-sonográfica do desenvolvimento embrionário-fetal de ovinos da raça Santa Inês. Ciên. Anim. Bras. 9, 148-155.

Moreno, C., Steinmann, C.C., Bickhardt, K., 1996. Fetal heart rate measurement and sonographic fetometry for determination of fetal age in sheep. Deut. Tierarztl. Woch. 103, 478-480.

Rihab, M.A., Bushra, H.A., Salah, M.A., Mohamed, T.I., 2012. The accuracy of gestational age predicted from femur and humerus length in Saanen goats using ultrasonography. Acta Vet. Brno. 81, 295-299.

Souza, J.M.G., Gomes, L.M., Monteiro Jr, P.L.J., Bruschi, J.H., Viana, J.H.M., Camargo, L.S.A., Fonseca, J.F., 2007. Uso de protocolos curtos para indução de estro em ovelhas Santa Inês - use of short-term protocols to estrous induction in Santa Inês ewes. XVII Congresso Brasileiro de Reprodução Animal.

Unno, N., Wong, C.H., Jenkins, S.L., Wentworth, R.A., Ding, X.Y., Li, C., Robertson, S.S., Smotherman, W.P., Nathaniel, P.W., 1999. Blood pressure and heart rate in the ovine fetus: ontogenic changes and effects of fetal adrenalectomy. Am. J. Physiol. 276, 248-256.

Valasi, I., Barbagianni, M.S., Ioannidi, K.S., Vasileiou, N.G.C., Fthenakis, G.C., Pourlis, A., 2017. Developmental anatomy of sheep embryos, as assessed by means of ultrasonographic evaluation. Small Rumin. Res. 152, 56-73.

Wilkins, J.F., 1986. Detection of pregnancy and embryos in ewes before day 30 using ultrasound imaging. Proc. Aust. Soc. Anim. Prod. 17, 48. 